\title{
Personal Orientation: The Silent Player in Efforts to Improve Treatment Seeking-Behavior Regarding Malaria in Uganda
}

\author{
Ahimbisibwe B Frank \\ Mbarara University of Science and Technology \\ Matagi Leon \\ Makerere University \\ Senkumba Mohamed \\ Makerere University \\ Atuhaire Privah \\ Makerere University
}

\begin{abstract}
Uganda government and development partners have engaged in various communication activities and programs with a view to change people's behaviors regarding malaria, mobilize communities and create an enabling environment for sound health practices. However, malaria has remained one of the leading causes of mortality and morbidity in Uganda. All players in the communications effort against malaria had a goal of reducing malaria-related mortality and morbidity by $70 \%$ by 2015 . It was not clear whether this was achieved since another strategic objective proposed in 2015 was that at least $85 \%$ of the population should undertake correct practices in malaria prevention and treatment by 2017.
\end{abstract}

\section{$>$ Objective:}

To get evidence-based knowledge in order to establish the contribution of individuals' personal orientations in predicting behavior that could increase their active involvement in seeking timely appropriate treatment for malaria or suspected malaria.

$>$ Method:

A cross-sectional survey using a correlational design was employed on a clustered sample of $\mathbf{3 8 0}$ rural households in 05 sub-counties of Kanungu district. Data was collected using researcher-administered questionnaires, key-informant interviews and focus group discussions.

$>$ Result:

There was a significant positive relationship between Personal orientation and treatment seeking behavior $(r=405 * *, P=<0.0)$.

\section{Conclusion:}

More communications effort should be laid on bridging the gap between individual's personal orientations towards seeking treatment against malaria in Uganda.

Keywords:- Personal Orientation, Treatment seeking behavior.

\section{INTRODUCTION}

In Africa, malaria is still one of the leading causes of mortality and morbidity in for example, Uganda (Musoke, 2015), Kenya (Munguti, 2009), Ethiopia (Deressa, 2012), Rwanda (Ngoboka, 2015). In 2013, malaria killed 30,919 people in DRC; 7,277 in Uganda; 8,528 in Tanzania; 6,294 in Burkina Faso; 4,349 in Cameroon; 4,326 in Seirra Leone; 3,723 in Malawi; 3,548 in Zambia; 7,300 in Angola; 7,878 in Nigeria and 409 in Rwanda (WHO, 2015).

In Uganda, 375,000 people in 10 districts of Northern Uganda contracted malaria within only 03 Months (April, May and June 2015) (New Vision, July 23, 2015). Earlier, the 2009 Malaria Indicator Survey (MIS) in Uganda together with the 2010 Malaria Atlas Project (MAP) showed that the country has a stable perennial transmission in $90-95 \%$ of the country. No wonder therefore, that in Uganda malaria accounts for 30\%-50\% of outpatient visits (Ministry of Health, 2014) and 15\%-20\% of hospital admissions (Nankabirwa et al, 2012).

In the late 1990s, malaria began to receive renewed attention, particularly after the 1998 creation of the global Roll Back Malaria Partnership (RBM). In 2000, all nations agreed to global malaria targets as part of Millennium Development Goals (MDGs). Since then, expanded efforts by donor governments, multilateral institutions, and affected countries helped to increase access to malaria prevention and treatment (Kaiser Family Foundation, 2014). However, studies on treatment seeking behavior (Renthlei \& Manoj, 2012) continue to show reliance on self-treatment as the first option.

By 2013, a number of global efforts and programs were in place to address Malaria. One of such programs was the 2005 US President's Malaria Initiative (PMI) that began as a 5-year, US $\$ 1.2$ billion expansion of US government's resources to reduce the burden of malaria and help relieve poverty in Africa. PMI intended to reduce malaria-related deaths by $50 \%$ in 15 African countries that had a high burden of malaria by expanding coverage of highly effective malaria prevention and treatment measures. By 2008, PMI's strategy was revised to achieve Africawide impact by halving the burden of malaria in $70 \%$ of atrisk populations in sub-Saharan Africa or approximately 450 million people, Uganda inclusive. 
Studies done in South-western Uganda and Northern Tanzania (Oberlander \& Elverdan, 2000) indicated that most people $(80.7 \%)$ were aware of how malaria is transmitted and prevented or treated. However, the same research found out that $74.5 \%$ did not utilize this awareness to get appropriate treatment in health facilities. No wonder therefore that recent research (WHO, 2013) has shown that globally, Uganda has the third highest number of deaths from malaria, and some of the highest reported malaria transmission rates in the world occur in Africa.

Health orientation is defined according to Basu, A., \& Dutta, M. J. (2008) as a person's motivation to engage in healthy attitudes, beliefs and behaviors, meaning an individuals inclination towards towards own health. Researchers Jayanti, R.K., Burns, A.C. (1998), Moorman, C., \& Matulich, E. (1993) describe the importance of an individual's personal health orientation in as far as an individual opts to take responsibility for their own health outlook. They argue that persons who are highly orientated on their health status are personally motivated to look for, give attention and understand health information plus engaging in practical overt healthy behavior.

Dutta (2005) posit that this health orientation is an intrinsic disposition rather that an environmental situations prompted feeling. More research on factors that motivate individuals to take interest in their health is provided by Maclnnis, Moorman \& Jarwoski, 1991. They found out that health motivations varied intra and across populations with resultant variations in health behaviors.

\section{METHODS AND MATERIALS}

A cross-sectional survey, correlational and descriptive, community-based among a randomly clustered sample of 380 rural households in five randomly selected sub-counties of Kanungu was done using questionnaires and focus group discussions. With the help of the District Health Officer, purposive sampling was used to zero on the five sub-counties for the study (Kambuga, Rugyeyo, Nyamirama, Kirima and Kanyantorogo) based on malaria prevalence. All the sub-counties of Kanungu had a minimum of four parishes and a maximum of six. Therefore, to ensure a balanced representation, four parishes were considered for this study and identified with the help of the VHW according to his knowledge of malaria prevalence. The number of households for the study sample was derived using Krejiec \& Morgan (1970) table for determining sample size.

At the time of data collection (October 2016-January 2017), Kambuga sub-county had the following five parishes: Bugongi, Kiringa, Nyarugunda, Nyarutojo and Ruhandagazi. Rugyeyo sub-county had the following six parishes: Nyarurambi, Kitojo, Kayungwe, Mishenyi, Kashojwa and Katungu. Nyamirama sub-county had five parishes: Mashaku, Nyakashure, Ntungwa, Nyarurambi and Kigarama. Kirima sub-county had the following four parishes: Bushura, Rubimbwa, Rutugunda and Kihanda. Lastly, Kanyantorogo sub-county had the following four parishes: Kihembe, Nyamigoye, Kishenyi and Burema. Quantitative approaches involved use of a questionnaire while Qualitative approaches were used in focus group and key informant interviews

Then, for the choice of households in each parish to participate in the study, no sampling was done because of uncertainty of finding participants at home. So the data collectors relied on availability of 'qualified' respondents to get a maximum of 19 households in each of the 4 parishes of the 5 selected sub-counties (19 households $\mathrm{x} 4$ parishes $\mathrm{x}$ 5 sub-counties $=380$ respondents). Nonetheless, care was taken to avoid concentrated interviews in concentrated homesteads.

This study was confined to adults aged 18 years and above mainly house heads who would satisfy the 'inclusion criteria' (having experienced fever that turned out to be malaria, or was suspected to be malaria during the one-year recall period).

Validity for each of the research instrument, nine Subject Matter Experts were engaged and required to provide their honest views on whether items in the research instrument represented the variables in question (Personal orientation or treatment seeking behavior) in terms of readability, clarity and comprehensiveness. The feedback was calculated into a $c v i$ for the entire questionnaire (highest cvi was 1.0 while the lowest was 0.86.) implying that all questions lay within the limits.

Reliability of the pilot questionnaire was determined through a pretest on 40 respondents who were not to be included in the main study sample. Then, for the validity test, the KII checklist and FGD checklist were evaluated by 09 researchers (subject matter experts) prior to use for data collection. A Cronbach Alpha was also run and yielded acceptable values $(0.827)$

Ethical clearance was obtained from the University Research and Ethics Committee, Uganda National Council for Science and Technology, Office of the President of Uganda, Resident District Commissioner Kanungu, District Health Officer, and Local Council Chair persons of the subcounties where data was collected. Additionally, before data collection recruits were told what the study was all about, before consent to participate was requested. Particularly, all respondents were told clearly that they could decline responding to any question, or were free to pull-out of the interactions at any stage. After field data collection, transcription and coding, all voice data and the hard copy responses were kept securely. 
ISSN No:-2456-2165

\section{FINDINGS}

The table below presents the responses on each statement about an individuals personal orientation towards seeking for treatment. The responses were explained in terms of descriptive statistics which included; mean, standard deviation and total responses on either
Agree/strongly Agree or Disagree/Strongly disagree. The following scale was used during the interpretation of mean.

\begin{tabular}{|c|c|c|c|c|c|}
\hline & & Disagree & Agree & Mean & Std. deviation \\
\hline 1 & Malaria is not a very deadly disease & $324(86.2)$ & $50(13.3)$ & 1.82 & 1.151 \\
\hline 2 & $\begin{array}{l}\text { Malaria fever can actually go away } \\
\text { without taking drugs }\end{array}$ & $350(93.1)$ & $20(5.3)$ & 1.56 & .834 \\
\hline 3 & Malaria is of uniform kind & $263(70.2)$ & $67(25.1)$ & 2.09 & 1.227 \\
\hline 4 & $\begin{array}{l}\text { Tablets from the shops/pharmacies are } \\
\text { better than those from hospital }\end{array}$ & $256(67.3)$ & $97(25.9)$ & 2.30 & 1.452 \\
\hline 5 & There are many causes of malaria fever & $190(50.8)$ & $156(41.6)$ & 2.81 & 1.397 \\
\hline 6 & $\begin{array}{l}\text { Most malaria drugs in clinics are } \\
\text { ineffective }\end{array}$ & $274(73.1)$ & $48(12.8)$ & 1.93 & 1.102 \\
\hline 7 & Shivering is the same as malaria & $144(38.3)$ & $228(60.5)$ & 3.39 & 1.593 \\
\hline 8 & $\begin{array}{l}\text { Lab tests are not necessary to identify } \\
\text { malaria }\end{array}$ & $290(78.3)$ & $71(18.9)$ & 2.05 & 1.295 \\
\hline 9 & $\begin{array}{l}\text { Headaches indicate imminent malaria } \\
\text { fever }\end{array}$ & $182(48.4)$ & $186(49.5)$ & 3.08 & 1.557 \\
\hline 10 & $\begin{array}{l}\text { No need to consult a health worker before } \\
\text { taking malaria drugs }\end{array}$ & $293(77.7)$ & $78(20.7)$ & 2.11 & 1.298 \\
\hline 11 & Malaria fever does not cause death quickly & $313(83.7)$ & $58(15.5)$ & 1.85 & 1.084 \\
\hline 12 & Malaria fever intensifies at night time & $97(23.8)$ & $268(71.3)$ & 3.70 & 1.517 \\
\hline 13 & $\begin{array}{c}\text { Malaria is not a common ailment in our } \\
\text { village }\end{array}$ & $297(78.6)$ & $54(14.3)$ & 1.90 & 1.131 \\
\hline 14 & $\begin{array}{c}\text { Malaria doesn't kill more people than } \\
\text { HIV/AIDS }\end{array}$ & $290(76.7)$ & $68(18)$ & 2.04 & 1.268 \\
\hline 15 & $\begin{array}{l}\text { I know that a common ailment in our } \\
\text { home is malaria }\end{array}$ & $134(35.5)$ & $211(55.5)$ & 3.37 & 1.382 \\
\hline 16 & $\begin{array}{l}\text { I know that all fevers don't develop into } \\
\text { malaria }\end{array}$ & $202(53.8)$ & $158942)$ & 2.74 & 1.490 \\
\hline 17 & Witchcraft can cause malaria fever & $369(98.4)$ & $4(1.1)$ & 1.31 & .553 \\
\hline 18 & $\begin{array}{l}\text { I don't like taking/swallowing malaria } \\
\text { tablets }\end{array}$ & $261(69.2)$ & $104(30.2)$ & 2.23 & 1.463 \\
\hline 19 & I naturally hate injections & $144(38.1)$ & $223(61.6)$ & 3.35 & 1.642 \\
\hline 20 & $\begin{array}{l}\text { Hot thick millet porridge is good treatment } \\
\text { for malaria fever }\end{array}$ & $322(84.1)$ & 45 (11.9) & 1.65 & 1.100 \\
\hline
\end{tabular}

Table 1:- Respondents Personal orientations towards malaria and its treatment Source: primary data, 2017

In the table above, statements that reflect personal orientations and perceived awareness of individual respondents towards actual or suspected malaria are presented. Respondents were also asked about their general knowledge about malaria fever and the following are the aggregated responses. $324(86.2 \%)$ agreed that indeed malaria was a lethal disease which can not just cure without proper medication (350: 93.1\%). Interesting however, is the varied opinion about the cause of malaria. 50\% respondents (190) believed there are many causes of malaria fever thus laboratory tests are needed to identify malaria (290: 78.3\%). 268 respondents $(71.3 \%)$ recalled that malaria fever intensified during night time and there was almost equivalent opinion about 'headache' as an indication of imminent malaria attack (182: 48.4\% disagreed, 186: 49.5\% agreed). This level of awareness also extends to a realization that there is always a need to consult a health worker before taking malaria drugs (293:77.7\%), that 
malaria was a common ailment in the sampled community (297: 78.6\%), shivering was most likely associated with malaria attack (228: 60.5\%), most fevers develop into malaria (202: 53.8\%), witchcraft does not cause malaria fever (369: 98.4\%) and the perception that 'hot thick millet porridge' cures malaria was wrong (322: 84.1\%). Lastly, respondents showed a preference for taking/swallowing malaria tablets (261: 69.2\%) against use of injections (223: 61.6\%).

\section{DISCUSSION}

A Pearson's Correlation analysis was made in order to assess the level of association $\left(\mathrm{r}^{2}\right)$ between the variables under study.

\begin{tabular}{|c|c|c|c|}
\hline & Health communications & Personal Orientation/Awareness & $\begin{array}{c}\text { Treatment Seeking } \\
\text { Behavior }\end{array}$ \\
\hline Health Communications & 1.00 & & \\
\hline Personal Orientation/Awareness & $.172^{* *}$ & 1.00 & \\
\hline $\begin{array}{c}\text { Treatment Seeking } \\
\text { Behavior }\end{array}$ & $.312^{* *}$ & $.405^{* *}$ & 1.00 \\
\hline
\end{tabular}

**. Correlation is significant at the 0.01 level (2-tailed).

Table 2:- Inter-item Correlations

Source: extracted from raw data in SPSS

There is a significant relationship between health communication management and treatment seeking behavior $(\mathrm{r}=0.312 ; p=<0.01)$ in agreement with Malik EM et al, (2006). The interpretation here is that properly relayed and managed communication (strategies) lead to acceptable treatment seeking behavior to a contribution of 0.312 and the reverse should also hold true. A poorly designed communications environment reduces acceptable behavior by a similar percentage.

Also, the results showed a significant relationship between Health communication management, personal orientation/awareness. (Test: $\mathrm{r}=0.172 ; p=<0.01$ ). This implies that when people and communities are more exposed to health communication messages, their level of awareness on malaria related issues improves by 0.172 according to this study. This, however appears a relatively weak relationship given the peculiarities of the study area (rural area with no TV sets, no current Newspapers in villages) thereby current messages don't reach timely.

Then, lastly, there is significant relationship between Personal orientation/awareness and treatment seeking behavior. (Test: $\quad r=0.405 ; \quad p=<0.01$ ) Attitudes and beliefs here are seen to influence treatment seeking behavior by 0.405 . These attitudes are shaped by by the level of awareness that is created by health information managers in various behavioral change programs as seen in literature review and as shall be discussed shortly.

This finding above are inline with literature (Malik, E., Hanafi, K., Ali, S., Ahmed, E., \& Mohamed, K. (2006), Munguti, \& K, J. (1998), which already observed that Personal orientation and treatment seeking behavior have been found to have a relationship. Perceptions of causes of illness and differences in biomedical and traditional illness concepts can hinder prompt access to effective treatment. For example, convulsions may be a sign of severe malaria, but in some parts of Kenya and Uganda, they are associated with supernatural powers, which require the use of traditional healers and therefore not referred to western medicines. This line of argument is in line with a study in Gambia that revealed that when malaria cases present with symptoms such as convulsions, hallucinations and/or loss of consciousness, a traditional healer was the first option for treatment seeking.

They also reflect the health belief models which propose that a person's health-related behavior depend on the person's perception of the severity of a potential illness, the person's susceptibility to that illness, the benefits of taking a preventive action, and the barriers to taking that action explain this study finding about the relationship between personal awareness and behavior.

Key informants (KI) in our study observed: '...some people think that fever can ease by itself and malaria isn't that fatal' (KI, male). 50 (13.3\%) respondents in the House Hold questionnaire agreed with the position above. '..If one is aware that symptoms and signs are for malaria, he/she is likely to go to a health center or hospital' (Local leader, from Kanyantorogo). '...yes, awareness improves treatment seeking behavior because from our records at the district, more people are turning up for treatment in time before fever intensifies' (Health worker, Kanyantorogo). '....yes, but I don't know whether this is the explanation why we nowadays have many people at health centers suffering from malaria, or it is lack of medicines elsewhere or it is a season for malaria (VHT, Kirima). '.....nowadays people avoid causes of malaria. They close windows early and sleep under mosquito nets (Local Council 3 chairperson)

When asked about what may stop people from seeking prompt treatment like was found out by whenever they fell sick especially with malaria, key informants had this to say:

"..poverty and ignorance. There is mushrooming of unregulated drug shops and herbalists in rural areas' and towns and everyone think they know, when they don't. (Key Informant from Nyamirama) 
'.....some people still believe in traditional healers. But majority have a false belief that there are no drugs at the health centres so they choose not to come (HW, Rugyeyo)

'...rude language by health workers; not enough drugs; lack of staff all the time and poor patient care. (Village Health Worker, Nyarurambi-Nyamirama)

'....self medication and '... at times when they visit the health centre and they don't get drugs, they also fail to raise money to buy from the drug shops. They end up taking little doze and even take it irregularly. This is not prompt treatment. (Parish chief)

'.... There is ignorance that malaria can actually kill. Others go to the health center and there are no drugs. So the next time they get feverish, they don't think of formal health centers as priority.........' (Key informant, Local Council 1 Chairperson).

'...Ignorance and traditional beliefs (Village Health Team worker, female)

This element of ignorance seemed to cut through since most key informants raised it in the interactions with them.

In line with Stuart Hall (2000) who proposed the Reception theory of encoding and decoding which explains the stages of transformation of a message from origins to reception and interpretation, whether communicators design good messages, such messages are not passively accepted by the audiences before the same audience interprets that particular message in their own fashion and its meaning basing on their cultural backgrounds and or personal life experiences.

“.....People in this area majority do not seek treatment when they are sick because of increased technology. Most of them google about medication and go to the shop and buy and take. Very very very bad please.............poverty, some know even if they go to health centre they are not given attention fully and medication so they opt to be home or use local herbs. (Lab technician, male.)

“...people think laboratory tests are expensive. They shun testing for malaria parasites because they believe you are also testing for HIV whose results they are not prepared to receive. In addition, they fear laboratory results can bring about other ailments they didn't want known by the public." (laboratory technician, female)

In addition to the discussion above, people (256; $67.3 \%$ ) now know that malaria tablets are the same wherever you get them be it shops or government health centers, malaria drugs are effective $(274 ; 73.1 \%)$, there is need to consult health/medical workers before taking malaria drugs $(293 ; 77.7 \%)$ and that malaria has types for example typhoid $(263 ; 70.2 \%)$, most fevers actually develop into malaria $(202 ; 53.8 \%)$ and 369 respondents $(98.4 \%)$ were well aware that witchcraft does not cause malaria.

Consequently, when 217 respondents (57.6\%) experienced signs of fever in the evening, they would not wait for the following morning to seek treatment. Also, other good behaviors of medication adherence were found among 259 respondents $(68.9 \%)$ who said that they continued taking medicines even when they already felt better after a bout of fever, 234 respondents (62.2\%) said that notwithstanding use of herbs for treatment of malaria fever, they would still go to formal health facilities, 323 respondents $(85.4 \%)$ would not simply take malaria medicines because of a headache and 319 respondents $(85 \%)$ knew that it was a bad practice to share malaria drugs with other family members.

This study also found out that respondents $(284 ; 75.1 \%)$ knew that a doze of malaria drugs was not uniform but depended on a several other factors like age, weight, amount of parasites detected, length of time with symptoms. A very good number of respondents (322; $85.5 \%$ ) knew that malaria was best treated by medical workers and 367 respondents $(97.1 \%)$ would not wait for a Village Health Team worker before seeking treatment for malaria upon experiencing symptoms. Thus, 299 respondents $(79.3 \%)$ said that they never waited to see whether it was malaria before seeking treatment in a health facility.

\section{CONCLUSION}

This study found out that Personal Orientation/Awareness was the best 'game changer' in behavioral change. The higher the exposure to health communications, the higher the level of awareness. The higher the awareness an individual has on health related issues like treatment seeking time and days, the more likely such an individual will engage in acceptable treatment seeking behavioral actions.

Human nature is driven by beliefs and perceptions generated from the environments they live or operate in. Some beliefs are shaped by level of education and exposure while others are propagated by ignorance. These sources of human personal orientations should be harnessed by communicators to further public health programs especially in malaria prevention efforts and subsequent treatment seeking actions in the event of a malaria disease occurrence. There should be consistent research on how populations perceive public health interventions in prevention and treatment of malaria such that harmonized approaches are designed with possible positive outcomes. 


\section{REFERENCES}

[1]. Basu, A., \& Dutta, M. J. (2008). The relationship between health information seeking and community participation: The roles of health information orientation and efficacy. Health communication, 23(1), 70-79.

[2]. Deressa (2009) National Five-Year Strategic Plan for Malaria Prevention and Control in Ethiopia: 20062010. accessed

at http://www.biomedcentral.com/1471-2458/9/259

[3]. Deressa, W., Woyessa, A., Ali, A., \& Lindtjørn, B. (2012). Prevalence of malaria infection in Butajira area, south-central Ethiopia. Malaria journal, 11(1), 84.

[4]. Dutta-Bergman, M. (2005). Developing a profile of consumer intention to seek out additional information beyond a doctor: The role of communicative and motivation variables. Health communication, 17, 1-16.

[5]. Dutta-Bergman, M. J. (2005). The readership of health magazines: The role of health orientation. Health marketing quarterly, 22(2), 27-49.

[6]. Dutta-Bergman, M. J. (2005). The relation between health-orientation, provider-patient communication, and satisfaction: an individual-difference approach. . Health communication, 18(3), 291-303. Retrieved from https://www.ncbi.nlm.nih.gov/pubmed/16187933

[7]. Ivan, N. (2015). How will Africa ever eradicate malaria? . Kigali: The New Times.

[8]. Jayanti, R.K., Burns, A.C. (1998) The antecedents of preventive health care behavior: An empirical study. J. of the Acad. Mark. Sci. 26, 6 . https://doi.org/10.1177/0092070398261002Deborah J. MacInnis, Christine Moorman and Bernard J. Jaworski.(1991) Journal of Marketing, Vol. 55, No. 4, pp. 32-53

[9]. Keizer Family Foundation Report 2014 accessed at http://kff.org/global-health-policy/report/globalfinancing-for-malaria-trends-future-status/

[10]. Malik, E., Hanafi, K., Ali, S., Ahmed, E., \& Mohamed, K. (2006). Treatment-seeking behaviour for malaria in children under five years of age: implication for home management in rural areas with high seasonal transmission in Sudan. Malaria journal, 5-60.

[11]. Ministry of Health, Uganda (2014) accessed at http://www.pmi.gov/docs/default-source/defaultdocument-library/malaria-operationalplans/fy14/uganda_mop_fy14.pdf?sfvrsn=14

[12]. Moorman, C., \& Matulich, E. (1993). A model of consumers' preventive health behaviors: The role of health motivation and health ability. Journal of Consumer Research, 20, 208-228

[13]. Munguti, \& K, J. (1998). Community perceptions and treatment seeking for malaria in Baringo district, Kenya: implications for disease control. East African medical journal, 75(12), 687-691. Retrieved from https://www.ncbi.nlm.nih.gov/pubmed/10065206
[14]. Musoke, D., George, M., Karani, G., Morris, K., Kasasa, S., Ndejjo, R., . . . Miph, B. M. (2015). Promising perceptions, divergent practices and barriers to integrated malaria prevention in wakiso district, uganda: a mixed methods study. PLOS ONE, 10(4). Retrieved from http://journals.plos.org/plosone/article?id=10.1371/jou rnal.pone.0122699

[15]. Nankabirwa, J., Yeka, A., Gasasira, A., Mpimbaza, A., Achan, J., Nsobya, S. R., . . . Kamya, M. R. (2012). Malaria in Uganda: challenges to control on the long road to elimination. I. Epidemiology and current control efforts. Acta Tropica, 121(3), 184195. Retrieved from https://www.ncbi.nlm.nih.gov/pmc/articles/PMC3156 969/

[16]. Oberlander, \& Elverdan. (2000). Malaria in the United Republic of Tanzania: cultural considerations and health-seeking behavior. Bulletin of the World Health Organization, 78(11), 1352-1357. Retrieved from http://www.ncbi.nlm.nih.gov/pubmed/11143196

[17]. Renthlei, L., \& Manoj, V. M. (2012). Health-seeking behaviour for febrile illness in malaria-endemic Kolasib district, Mizoram, India. Journal of international health, 4(4).

[18]. Roll Back Malaria Partnership (2015) accessed at http://www.rollbackmalaria.org/news-events/latestnews

[19]. Roll Back Malaria. (2005). Global Strategic Plan 2005-2015. Geneva: World Health Organization.

[20]. Stuart, H. K. (2000). Reception Theory. Retrieved from SlideShare: https://www.slideshare.net/alexeglen/stuart-hallsreception-theory

[21]. World Health Organization (2015) Malaria Report 